\title{
Redefining the Management Roles: Response to Digital Networking and Access to a Large Amount of Information
}

\author{
Maja Strugar Jelača \\ University of Novi Sad, Faculty of Economics in Subotica, Subotica, Serbia
}

\begin{abstract}
The achievements of digital age lead to necessary transformation of current elements of management into the new successful composition of modern management in the 21st century. Digitization has affected new ways of monitoring business processes, employees and external stakeholders, causing a large amount of information to be processed and treated in the right way. In such a business environment, a new mindset of managers is required, the one that relies on social intelligence, media literacy, computer-like thinking and virtual collaboration.

The topic of the research is the analysis of implementation of innovative interpersonal, information and decision-making role. The aim of the paper is to determine the need for redefining the existing management practices into innovation-oriented one.

On the one hand, on the path of transformation of management roles there will be application of high density digital social networks and decentralization in order to multiply business relationships and form a large information database in which managers can be found as recipients, senders and spokespersons of information. The above mentioned networks should be oriented to networking with external stakeholders to provide market intelligence. In this way, managers access diversified information easier and faster and should recognize their compatibility with an organization's nature and business area. On the other hand, managers are faced with a new strategic framework that indicates a set of possible decisions when assimilating and exploiting obtained information. Also, managers are challenged to leave the common decision-making path, which in many cases results in adoption of routine business decisions, and to move towards a non-linear and unstructured decision-making process, leading to the adoption of creative and innovative business decisions. The goal is forming a paradoxical decision-making framework that allows innovative behavior of organization, by making business decisions which are flowing towards situational changes and enabling realization of longterm sustainability in business. Since a manager as an individual decision maker can process only a smaller amount of new information, trends point to application of joint decision-making model.

Implementation of innovative management roles was analyzed in 50 large companies on the territory of the Republic of Serbia. Analysis was performed using the Mann-Whitney test and correlation analysis. Research results indicate the existence of differences in organizations' level of innovation, depending on whether they apply innovative oriented interpersonal roles and decision-making roles or not. Also, statistically significant correlation of high intensity emerged between the use of innovative oriented interpersonal management roles and the degree of innovation in organization, and medium intensity correlation between the application of decision-making role and organization's degree of innovation. The above mentioned results of the study indicate the importance of redefining management roles through focus on innovation and the role of interpersonal and decision-making roles, applying new business models.
\end{abstract}

\section{Keywords}

Information role, decision-making role, digital social networks, the theory of information processing. 


\section{Introduction}

In a modern business environment, the basic task of managers is to create an innovative and sustainable working environment in which employees can fulfil their obligations and set goals by applying the principle of collaboration (Tengblad, 2006; Akhtar, 2011; Ramezani Khabiri, Alvani, \& Tondnevis, 2011, p. 559). Innovatively oriented managerial roles of managers who keep the pace with the everincreasing innovations in the digital era should provide creative and innovative thinking at all hierarchical levels in organization in order to create an innovative organizational culture. Such organizational culture will stimulate the continuous realization of better performance. Therefore, the subject of the research is the analysis of innovative implementation of interpersonal, information and decision-making role, where innovations in the area of digitization have the greatest impact on information roles and decision-making roles. For this purpose, it is necessary to carry out the observation of the traditional groups of management roles (Mintzberg, 1975) through the framework of innovative management, in order to distinguish those that managers need to apply in the digital era. This would determine the need to redefine the existing management practice into an innovative oriented one, which is the aim of this research.

Both internal and external variables have a critical impact on the nature of management roles. Some of the critical factors of impact are organizational climate, nature of work, mindset of managers and other employees, as well as their relationship on the one hand and the situation in the environment on the other, taking into account the degree of dynamism and innovation. Identified critical factors should be considered from an innovative angle. In that way, we can determine the need and the possibility of innovating managerial practice with the aim of improving managers' and employees' creativity, identifying a continuous training program in response to technological progress and innovative trends of all participants in the environment.

Observing the management roles, the path of achieving greater innovation of the organization is reflected in: leadership behavior of managers aimed at accepting risks in order to achieve the greatest possible innovation; directing managers to create links through greater openness to make new acquaintances and the possibility of successful collaboration in the future; the openness of management to the inflow of new information with the aim of sharing them with all employees and combining in different ways; orientation of managers as decision makers to anticipate future chances on time, proactive action and making creative decisions.

\section{Classification of management roles}

One way of explaining managerial practice is through the analysis of the applied managerial roles defined by the author, H. Mintzberg. The aforementioned author points out three basic groups of management roles stemming from one another.

Interpersonal roles as the first group of management roles derive from the authority and relationship at the manager-employee level and the manager-other participants in the business level. The group of interpersonal roles includes:

- Managers who have a role of a leader, deriving from the position of managers in the organization and with the routine character. It involves carrying out various ceremonial duties which requires adequate representation of the organization to other market participants. Method of this role's implementation influences created reputation of an organization as well as an opinion from the perspective of competitors, business partners and consumers, who will therefore make decisions about business or consumption in the future.

- Managers as leaders who have the power to persuade employees and lead the organization in order to achieve positive business results. The tasks of managers on this path are: motivation, encouragement and continuous training of employees, which affects dedication, productivity and quality of the work force.

- Managers who have the role of creating links, both internal and micro-links to employees at all levels along a hierarchical scale as well as a macro connection with external market participants. Another division of relationships relates to their nature, which can be business or political. Business relationships arise as a relationship: management - top management of other organizations, manager - suppliers, manager competitors and manager - business 
partners, while political relationships develop as a relationship: manager - state authorities. The intensity of mentioned relationships can be strong or weak, which affects the quality of the results of the established relationship, that is: secrecy, reliability, timely information and their maximum usefulness on the one hand and unreliability, obsolescence and inability to process such information on the other. The strength of relationships depends on a number of factors, such as: available time, emotional state, degree of intimacy and reciprocity (Granovetter, 1973, p. 1361). In this way, an external information system is formed, which represents the database, together with internal information, for making decisions, strategies and goals (Strugar Jelača, 2015, p. 99).

Information roles constitute the second group of management roles and are based on information gathered from interpersonal manager relationships. Within this group of roles, the main task of the manager is to collect as much information as possible using new channels of communication, and to make their selection in order to form a database of relevant information that will ensure more efficient management and proactive decision-making. Within this group of roles, the following manager roles are distinguished:

- Recipient of information, who has the task to continuously scan and control internal and external business environment. When implementing this role, it should be taken into account that information is not knowledge (Deming, 1996, p. 95) and that they should be analyzed in accordance with the defined criteria in order to ensure their quality application and produce real new knowledge.

- Information provider has the task of minimizing the emergence of a centralized information base that is available only to managers, but should ensure their timely expansion in order to maximize utility. Therefore, in this situation managers need to determine which information should be passed, when and who to. Therefore, the formation of a decentralized information system is encouraged, which will enable dissemination of privileged information, with the full implementation of the principles of secrecy and confidentiality towards external participants.

- A spokesman who has the task of informing the general public, or interested external stakeholders. The fund of this information greatly influences functioning of these groups in the near future, such as the steps of business partners on the topic of joint activities, consumers in the form of their further purchases and loyalty, as well as the moves by competitors in the field of imitation or counteraction.

The formed information base should be the basis for implementing managerial role of managers such as the role of decision making. This group of roles is implemented through the following individual roles:

- Manager as an entrepreneur should recognize the chance at the right time, and initiate the change and implementation of innovative activities in order to use it. Also, it is necessary to be a person of the idea, which will encourage formation of effective project proposals within the project portfolio and conduct constant monitoring of project results.

- Problem solving manager is a manager who, on the path of introducing novelties into existing business practices, is faced with a situation of discontinuity and possible conflicting situations that need to be corrected in time. There is a wide range of possible problems, some of which are internal, such as employee resistance to introduced changes, misunderstanding of new ways of doing business or the inability to implement newly set tasks, as well as problems of an external nature such as loss of business partners, termination of previously concluded business contracts, loss of major suppliers, etc. (Strugar Jelača, 2015, p. 101). Therefore, the manager should be responsible for resolving conflicts and removing obstacles that hinder cooperation or make it difficult (Deming, 1996, p. 59).

- The manager in the role of resource allocator has the obligation to provide necessary resources for the realization of the desired novelties, as well as the solution of the problems that were created, and then to perform an efficient allocation of resources. This role should be 
implemented by the principle of identifying priority innovative activities along with the parallel implementation of the principle of minimizing wastage of available resources.

- The manager as a negotiator should contact and contract with adequate business partners in order to ensure the successful realization of innovative activities while achieving synergistic effect. The manager should act as a negotiator along the whole innovation cycle - from the proposal to realization - and even afterwards when it is necessary to ensure adequate implementation of innovations.

An efficient manager should not be directed to individual application of management roles, but on the integrated and parallel implementation of all the roles, taking into account their interdependence and need for coordination.

\section{Innovative framework of management roles as an answer to the changes in digital era}

The way in which the role of interpersonal groups is carried out is directly related to the manager's mental set. Therefore, implementation of innovative-oriented interpersonal roles correlates with manager's innovative capacity, such as existing expertise, possibility and the desire to acquire new knowledge that will focus on creative problem solving. These elements represent inputs, while under the effects of applying interpersonal management roles innovative performance at the level of the whole organization is reflected. In order to do this, interpersonal relationship between managers and employees should go in the direction of: participatory involvement of employees and group thinking, use of creative potential and specialized knowledge of employees, encouraging innovative performance of employees together with their personal satisfaction. Managers who possess a wide range of skills and expertise have the opportunity to realise interpersonal roles in an innovative manner. In the role of a frontman, they perform routine business obligations of social interest in a new way by propagating the innovative work of the organization. In the role of a leader, they lead the organization with the maximum use of available and hidden innovative potential of employees. In the role of link creators, they encourage the creation of a broad base of new knowledge that is realistic and compatible with the business ideology of the organization (Strugar Jelača, 2015, p. 172).

Since innovations mean the activities of processing information (Kleinschmidt, Brentani, \& Salomo, 2010, p. 200), one of the key innovatively motivated roles is a group of informative roles. The creation of an information base is carried out by creating traditional and virtual social networks. The theory of social networks points to all possible connections that are established in order to increase innovative level of business, such as links between employees and relationships with external members, in order to provide a greater degree of awareness of the changes and necessity of their implementation (Strugar Jelaca, 2015, p. 174). Within the mentioned theory we distinguish the networks of large and small density, with high density networks indicating all established interconnections between internal members of the organization as well as internal and external ones, while low density networks are of the most centralized character, which indicates a lower number of established connections between the mentioned group (Buchel, Nieminen, ArmbrusterDomeyer, \& Denison, 2013). A large number of established connections with external participants allow obtaining a wider differentiated information base, while a large number of internal links along the entire hierarchy scale allows the flow of large amounts of heterogeneous information, which can be combined in different ways and form different innovative results. Therefore, this type of network is characteristic of a modern business environment, especially when using diversified new ways of communication based on digitization. It also provides information flow in both directions from external participants to management and from management to all employees. High density networks on the one hand have higher innovative potential but their constant analysis is necessary in order to form the basis of objective and real knowledge, while centralized networks on the other hand have less innovative potential and therefore are less demanding when it comes to coordination and collaboration. Social networks are classified also based on the strength of the links within them, which can be strong or weak. Strong networks lead to active, constant and solid collaboration among participants, which facilitates information exchange, enables acquisition of useful information and encourages greater transparency. 
However, one of the shortcomings of these relationships that often take a routine character is that they are constantly being implemented and most often among members of the same area, which leads to a lower degree of novelty. Week networks are based on new relationships that are just established, which are occasional and therefore can lead to major novelties. The emphasis is on the formation of as many networks using innovative communication channels, but not only putting emphasis on quantity, but also on the quality of established connections, which directly determines usefulness of the information received.

In addition to the need to establish a large number of innovative social networks, innovative implementation of information roles requires application of the theory of organizational processing of information when implementing innovative activities. All members of an organization should be focused on processing information on the market, technological changes, competitor organizations and resources in order to implement their transformation into an innovative strategy (Moenaert, Caeldries, Lievens, \& Wauters, 2000, p. 361). By applying this concept of learning, organizations become market intelligent acquiring new external information on economic, political and social changes that have impact on organizational business, latent consumer needs, and technological changes (Slater \& Narver, 1995), on the one hand, as well as information on business ideology and values that are being strived for, which directly defines the conceptual framework for information processing. Strategic position of the organization influences the scope of the access to global information, while the possibility of interaction between managers and employees with geographically dislocated sources of information depends on the established channels of communication, their ability to access diversified information and their compatibility with the nature of the organization and the area in which it operates (Strugar Jelača, 2015, p. 176). However, a number of organizations do not use the theory of organizational processing that leads to their shortsightedness, under the influence of a strategic myopia, and to a stereotyped view of managers trapped in the framework of their previous knowledge and inert to new information. This behavior causes the organization's innovative activity to stifle. It is necessary to establish a balance in the processing of the information obtained taking into account financial aspect, providing the desired benefit of the information received and the acceptable cost of arriving thereon. The ultimate result of processing new information should be their sharing. The process of sharing can be characterized as a process of distributing information about consumers and competitors among the employees of all departments, which will lead to a general understanding (Sinkula, 1994) of the business environment with the formation of a new perception of the market situation. Employees who are part of sharing system have a sense of belonging, often identify with the organization, establish intense coordination and communication with others, which leads to a more creative and innovative approach to business, while minimizing possible conflicts and confrontations. Strategic decision-making has long been one of the central managerial activities in all organizations, whether they are small, large, nonprofit, profitable, public or state owned (Elbanna \& Child, 2007, p. 562). Information capacities within the decision-making process are therefore managers who absorb and process information about a problem or business opportunity with the aim of choosing new strategic options. When making decisions, individuals are rationally restricted which in some cases leads to incomplete understanding of the strategic position of an organization and turns to application of cognitive frameworks that influence the formation of a subjective view of the environment, leading the process of making strategic decisions and business actions (Nadkarni \& Barr, 2008, p. 1395). Then stereotypical decisions are made that limit innovative behavior. A modern business environment requires implementation of a creative and innovative decision-making process characterized by non-linearity and absence of structure, which carries with it a greater risk with the possibility of radical progress or erosion of business. Prior to this, the entrepreneurial character of managers is emphasized when making innovative decisions, taking into account differentiated perspectives. Depending on whether stereotypical or creative decisions are made, the managerial decision-making process that can be routine-business or paradoxical depends on it. The paradoxical decision-making framework allows managers to make decisions in line with situational changes aimed at achieving long-term sustainability of operations. In this type of decision-making, contradictory forces from the environment forming the information base are 
taken into account and include a large number of quantitative, qualitative, financial and nonfinancial information (Hanh, Preuss, Pinkse, \& Figge, 2014, p. 470). By combining various information interactions, there is a set of alternative decisions among which one should choose the optimal one that will secure the position of a true leader and pioneer innovator. Also, application of the paradoxical framework requires implementation of a collective decisionmaking model because the manager as an individual decision maker can process a limited amount of information at the same time (Arendt, Priem, \& Ndofor, 2005, p. 681).

Based on the previously presented theoretical framework, the following research hypotheses have been identified:

1. There is a difference in achieving innovative performance at the organization level, depending on the nature of the application of management roles.

2. There is a positive link between the level of innovation and the application of innovative leadership roles.

\section{Methodology and research results}

The questionnaire is structured in three parts, where the first part of the questionnaire analyzes basic characteristics of the surveyed large legal entities and their management, the second part analyzes implementation of innovative management practice through analyzing implementation of all the three groups of management roles by respondents, and the third part analyzes innovative business results for a period of 5 years, taking into account the number of all kinds of innovations. The questionnaires were distributed to 70 e-mail addresses of managers of large legal entities in the territory of the Republic of Serbia. There were 52 completed questionnaires, with three questionnaires considered invalid because they did not provide answers to all the questions. Given that 70 questionnaires were sent and 52 completed ones were received, in percentage $74 \%$ of survey respondents responded to the survey.

Using Mann-Whitney non-parametric test, H1 hypothesis testing was conducted to determine if there was a difference between managers' management roles and the degree of innovation of the organization.
Table 1 Mann-Whitney test

\begin{tabular}{l|c|c|c}
\hline $\begin{array}{l}\text { Innovative } \\
\text { managerial practice }\end{array}$ & $\begin{array}{c}\text { Number of } \\
\text { companies }\end{array}$ & $\begin{array}{c}\text { Mean } \\
\text { ranks }\end{array}$ & $\begin{array}{c}\text { Sum of } \\
\text { ranks }\end{array}$ \\
\hline $\begin{array}{l}\text { Traditional } \\
\text { interpersonal roles } \\
\text { Innovative-oriented } \\
\text { interpersonal roles } \\
\text { Total }\end{array}$ & 29 & 17.83 & 517.00 \\
\hline $\begin{array}{l}\text { Traditional } \\
\text { information roles } \\
\text { Innovative-oriented } \\
\text { information roles }\end{array}$ & 20 & 35.40 & 708.00 \\
\begin{tabular}{l} 
Total \\
\hline $\begin{array}{l}\text { Traditional } \\
\text { decision-making } \\
\text { roles } \\
\text { Innovative decision- } \\
\text { making roles }\end{array}$
\end{tabular} & 20 & 22.60 & 655.50 \\
\begin{tabular}{l} 
Total \\
\hline
\end{tabular} & 50 & 30.48 & 569.50 \\
\hline
\end{tabular}

Source: The author, adjusted according to Strugar Jelača, 2015, p. 237

The results of the conducted test indicate that there are differences in the level of innovation among organizations using innovative-oriented interpersonal (Man-Whitney $=82,000$; Asymp. $\mathrm{Sig}=.000)$ and decision-making roles (ManWhitney $=163,500 ;$ Asymp. Sig $=.007$ ) compared to those using traditional management roles.

Table 2 The difference in the degree of innovation of the organization in relation to the nature of the applied management roles

\begin{tabular}{l|l|l|l}
\hline & $\begin{array}{c}\text { Interpersonal } \\
\text { roles }\end{array}$ & $\begin{array}{c}\text { Information } \\
\text { roles }\end{array}$ & $\begin{array}{c}\text { Decision- } \\
\text { making } \\
\text { roles }\end{array}$ \\
\hline Mann- & & 220.500 & 163.500 \\
WhitneyU & 82.000 & 655.500 & 628.500 \\
Wilcoxon & 517.000 & -1.423 & -2.709 \\
W & -4.374 & .155 & .007 \\
Z & .000 & & \\
Asymp. & & & \\
Sig & & & \\
\hline
\end{tabular}

Source: The author, adjusted according to Strugar Jelača, 2015, p. 237

The following table shows the results of the correlation analysis carried out in order to test $\mathrm{H} 2$ hypothesis. The aim of the correlation analysis is to identify those management roles that stimulate a higher level of innovation of the organization. 
Table 3 Relationship between management roles and the degree of innovation of the organization

\begin{tabular}{l|l|l}
\hline Management roles & & $\begin{array}{l}\text { Innovation of } \\
\text { the } \\
\text { organization }\end{array}$ \\
\hline Interpersonal roles & $\rho$ & $.696^{* *}$ \\
& $\mathrm{p}$ & .000 \\
& $\mathrm{~N}$ & 49 \\
\hline Information roles & $\rho$ & .208 \\
& $\mathrm{p}$ & .152 \\
& $\mathrm{~N}$ & 49 \\
\hline Decision-making & $\rho$ & $.381^{* *}$ \\
roles & $\mathrm{p}$ & .006 \\
& $\mathrm{~N}$ & 49 \\
\hline \multicolumn{2}{c}{ Source: The author, adjusted according } \\
to Strugar Jelača, 2015, p. 237
\end{tabular}

The conducted correlation analysis points to the existence of a positive statistically significant strong correlation between the application of interpersonal management roles and the degree of innovation of the organization $(\rho=.696$; Sig. $=$. $000)$, while between the application of decision roles and the degree of innovation there is a statistically significant positive correlation of medium intensity $(\rho=.381$; Sig. $=.006)$.

Taking into consideration the questions from the questionnaire which describe each group of management roles, it has been established that a higher degree of organization's innovation depends on the manner in which the management roles are applied. A greater degree of innovation is achieved if the manager:

- represents the organization as an innovative oriented,

- encourages implementation of innovations in the business plan,

- constantly identifies ideas for innovation, which should have innovative potential, be realistic and can be successfully realized;

- considers himself an original and creative person and acts in accordance with that statement,

- successfully solves conflicts arisen by giving a constructive solution. Potential conflicts arise because each innovation leads to the breakdown of existing business routines, which leads to more frequent delays and problems,

- encourages negotiation and cooperation with business partners and thus achieves a synergistic effect and can realize financially more demanding and more risky innovative proposals,
- constantly strengthens and refreshes a network of contacts that directly affects the expansion of the information base and thus encourages the creation of new knowledge,

- has good relationships with clients and partners and easily enters joint ventures.

Previously conducted analyzes indicate the confirmation of both research hypotheses, so the companies that are striving for greater innovation should apply innovative-oriented management roles in the manner explained in the previous section.

\section{Conclusion}

The defined problem of the research is aimed at obtaining the answer to the research question: Does the implementation of managerial roles by managers of all levels in large organizational systems contribute to innovation in an environment that abounds in change? Taking into account the statement that organizational systems represent open business systems that are subject to change, empirical research has indicated that organizations that want to survive and grow by achieving greater innovation at the organization level and thus keep pace with innovations need to innovate managerial practice, transforming interpersonal and decision making roles. The two sets of management roles and their innovative implementation encourage greater innovation.

The interpersonal roles of managers, such as the frontman, the leader and the creator of the relationships encourage greater innovation of organizations. The manager as a leader presents the organization itself as an innovative oriented and thus encourages the search for potential areas of business that need to be innovated; the leader creates an adequate business environment by creating a healthy environment for innovation and defining business guidelines necessary to achieve the positive business results of an innovative management activity; a manager who constantly creates connections through the continuous improvement of personal communication network and establishes good relations with clients and partners appears as a driver of innovations (Strugar Jelača, 2015, p. 266).

The analysis of link between application of information roles and the degree of innovation did not reveal a statistically significant positive correlation. However, individual analysis of information roles indicates that managers, as both 
recipients and information and its providers, play an important role in growth of the degree of organization's innovation, especially in a modern business environment that abounds in new information and channels leading to it.

Observing the final managerial role of managers as decision makers, it has been identified that managers who take the role of a problem solver by finding new ways to solve them, as well as managers who establish business cooperation with potential partners in the area of joint implementation of innovations, encourage a higher degree of innovation of an organization.

Conducted research indicates theoretical framework as well as the suggested behavioral guidelines for managers that will enable more innovative behavior and business results.

\section{References}

Akhtar, S. (2011). Human Capital Utilization through Effective HRM Practices. Middle-East Journal of Scientific Research, 8 (2), 434-439.

Arendt, A. L., Priem, L. R., \& Ndofor, A. H. (2005). A CEOAdviser Model of Strategic Decision Making. Journal of Management, 31 (5), 680-699.

Buchel, B., Nieminen . L., Armbruster-Domeyer, H., \& Denison, D. (2013). Managing Stakeholders in Teambased Innovation - The Dynamics of Knowledge and Trust Networks. European Journal of Innovation Management, 16 (1), 22-49. doi: 10.1108/14601061311292841

Deming. E., (1996). Kako izaći iz krize. Beograd: PS Grmeč.

Elbanna, S., \& Child, J. (2007). The Influence of Decision, Environmental and Firm Characteristics on the Rationality of Strategic Decision-Making. Journal of Management Studies, 44 (4), 561-591.

Granovetter, M. S. (1973). The Strength of Weak Ties. American Journal of Sociology, 78 (6), 1360-1380.

\section{$凶$ Correspondence}

\section{Maja Strugar Jelača}

Faculty of Economics in Subotica

Segedinski put 9-13, 24000, Subotica, Serbia

E-mail: m.strugar.jelaca@ef.uns.ac.rs
Hanh, T., Preuss, L., Pinkse, J., \& Figge, F. (2014). Cognitive Frames in Corporate Sustainability: Managerial Sensemaking with Paradoxical and business Case Frame. Academy of Management Review, 39 (4), 463-487. doi: 10.5465/amr.2012.0341

Kleinschmidt, E., Brentani, U., \& Salomo, S. (2010). Information Processing and Firm-Internal Environment Contingencies: Performance Impact on Global New Product Development. Creativity and Innovation Management, 19 (3), 200-218. doi: 10.1111/j.14678691.2010.00568.x

Mintzberg, H. (1975). The Manager's Job: Folklore and Fact. Harvard Business Review, 53 (4), 49-61.

Moenaert, R. K., Caeldries, F., Lievens, A., \& Wauters, E. (2000). Communication in International Product Innovation Teams. Journal of Product Innovation Management, 17 (5), 360-77.

Nadkarni, S., \& Barr, P. S. (2008). Environmental Context, Managerial Cognition, and Strategic Action: An Integrated View. Strategic Management Journal, 29, 1395-1427.

Ramezani, Z. N., Khabiri, M., Alvani, S. M., \& Tondnevis, F. (2011). Use of Mintzberg's Model of Managerial Roles to Evoluate Sports Federations Managers of Iran. Middle-East Journal of Scientific Research, 10 (5), 559564.

Sinkula, J.M. (1994). Market Information Processing and Organizational Learning. Journal of Marketing, 58 (1), 34-45.

Slater, F. S., \& Narver C. J. (1995). Market orientation and learning organization. Journal of Marketing, 59 (3), 6374.

Strugar Jelača, M. (2015). Uticaj dinamike inovacija na kreiranje modela menadžment aktivnosti u organizacionim sistemima (Unpublished doctoral dissertation) Ekonomski fakultet u Subotici, Subotica.

Tengblad, S. (2006). Is there a new Managerial Work? A Comparison with Henry Mintzberg s Classic Study 30 Years Later. Journal of Management Studies, 43 (7), 1437-1461. 